


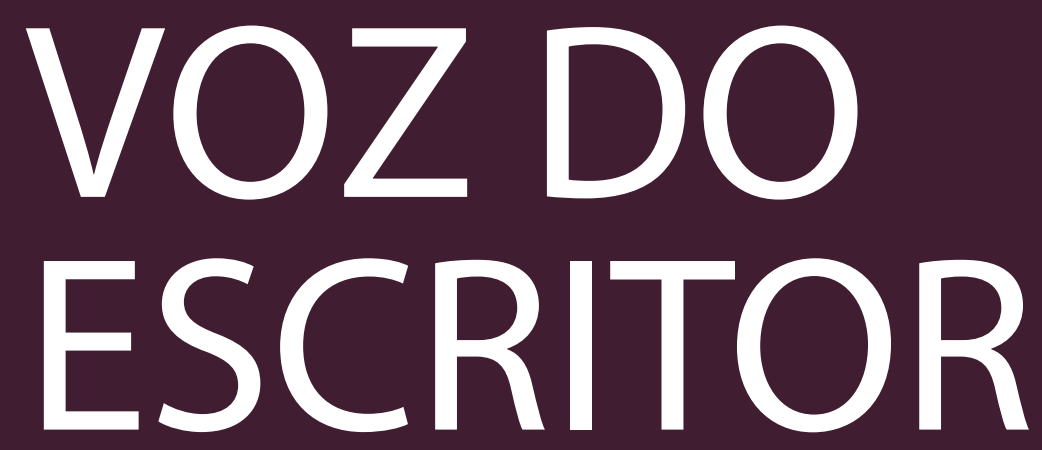




\section{AS VOZES DO FEMININO NA VOZ DE ANGÉLICA FREITAS}

- FÁTIMA GHAZZAOUI

$\mathrm{E}$

m Cartas a um jovem poeta, Rainer Maria Rilke aconselha seu remetente, o jovem poeta Franz Xaver Kappus, a não buscar nas exterioridades o valor do seu trabalho. Se efetivamente escrever era uma necessidade para ele, o escritor o aconselha a procurar em si mesmo as razões: "Procure entrar em si mesmo. Investigue o motivo que o manda escrever; examine se estende suas raízes pelos recantos mais profundos de sua alma; confesse a si mesmo: morreria, se lhe fosse vedado escrever?" (RILKE, 2013, p. 22). Mais adiante, Rilke também sugere que ele deve "fugir dos motivos gerais para aqueles que a sua própria existência cotidiana Ihe oferece" (idem, p. 23). Este parece ser o caminho que a escritora gaúcha Angélica Freitas seguiu ao publicar seu primeiro livro - Rilke Shake - em 2007. Jornalista de formação (UFRGS), não encontrou na rotina da profissão o tipo de escrita a qual almejava cultivar. Somente quando abandonou o jornalismo pôde se dedicar integralmente à literatura, sonho que a acompanhava desde a infância.

Seu livro de estreia reúne sua produção até aquele momento e revisita a tradição com humor e ironia. Porém, não se trata de imitá-la ou de reproduzi-la, e sim de sacudi-la e reinventá-la em contexto contemporâneo. Segue à risca o conselho de Rilke quanto ao modo de ser poeta: olha para si e está com os dois pés fincados no cotidiano, mas desdenha quaisquer motivos ou situações que na tradição possam aprisionar ou remeter a imposições sociais. Quer a tradição naquilo que ela tem de libertador; observa o que resta de sentido naquilo que foi a experiência do outro e toma para si o que há de verdade nessas vivências, trazendo-as como aprendizado capaz de iluminar suas próprias experiências na contemporaneidade.

O trocadilho do título, que dá nome a poema homônimo - "Rilke Shake"-, mostra bem o tipo de conexão que se realiza com a tradição. Quando a realidade perde o sentido e a melancolia toma conta da cena, misturar-se às experiências do passado pode trazer alguma esperança para o não sentido do presente, o que permite triturar camadas e mais camadas de perdas e recalques, como atestam os versos seguintes, em que uma tradição já "mexida" e "agitada" suscita no sujei- 
to lírico o desejo de conectar a si mesmo por intermédio das danças circulares dos dervixes, metáfora que de um lado conduz ao conhecimento de si mesmo e de outro promove a anulação da subjetividade. Nesse sentido, traços da tradição e traços da contemporaneidade se entrelaçam na experiência individual da poeta: "nada bate um rilke shake / no quesito anti-heartache / nada supera a batida / de um rilke com sorvete / por mais que você se deite / se deleite e se divirta / tem noites que a lua é fraca / as estrelas somem no piche / e aí quando não há cigarro / não há cerveja que preste / eu peço um rilke shake / engulo um toasted blake / e danço que nem dervixe." (FreITAS, 2007, p. 39).

Outro exemplo do modo como a poeta se aproxima da tradição pode ser visto no poema "estatuto do desmallarmento", em que o sujeito se serve da apostrofação lírica para estabelecer um diálogo irônico, no qual as experimentações da poesia pura de Mallarmé são sinônimo de perigo, de desestabilização do leitor que deveria, por isso, abdicar de arma tão perigosa: "estatuto do desmallarmento / minha senhora, tem um mallarmé em casa? / você sabe quantas pessoas morrem por ano / em acidentes com o mallarmé?" (idem, p. 53).

Diante do atual projeto de liberação do porte de armas e da explicitação de toda sorte de violência difundida pelo governo Bolsonaro, os versos de Angélica Freitas se tornam cada vez mais atuais, revelando o quanto é necessário munir-se de poesia para lutar contra a barbárie.

Nesse sentido, esse primeiro livro circula entre o passado e o presente da autora, tanto o passado familiar quanto o que construiu suas referências literárias e traz embrionário o que virá a ser o projeto temático dos livros subsequentes. A cada produção, o diálogo entre a tradição se acentua, inquirindo-a, questionando-a, valorizando os acertos, sem deixar de analisar as falhas e os limites históricos encerrados nas formas literárias tradicionais e nas convenções sociais de onde elas derivam.

Em 2012, Angélica Freitas publica Guadalupe, junto com o quadrinista Odyr Bernardi, espécie de road movie em quadrinhos. A narrativa é ambientada no México, onde a heroína constrói seu presente ao mesmo tempo que revisita o passado na figura da avó, que, antes de morrer, pede para ser enterrada em sua cidade natal.

Guadalupe foi criada por seu tio travesti. Na juventude, ele trabalhava em uma boate como dançarina e usava o pseudônimo de Minerva Maravilha, mas abandonou a carreira artística para abrir um sebo e cuidar da sobrinha que fora abandonada pela mãe. Com a morte da avó, Guadalupe e o tio levam o corpo para ser enterrado em sua cidade natal. No trajeto entre a Cidade do México e Oaxaca, Guadalupe se vê enredada por forças malignas que querem tomar a alma de sua avó. É neste momento que, com o apoio de um cogumelo ritual, Guadalupe se investe de uma força indestrutível e se transforma na heroína 
"Super Guadalupe"! Seguindo a tradição do road movie, o trajeto percorrido na viagem coincide com o percurso de autoconhecimento realizado pela heroína, de cuja transformação resultará seu empoderamento. A partir daí, ela tem total consciência do processo opressivo pelo qual passou sua avó, impedida de viver sua opção de gênero e obrigada a casar-se e constituir família nos moldes do cis-heteropatriarcado. Enterrar a avó em Oaxaca foi também revelar essa opressão, sempre calada e dada como natural. Nesse sentido, Guadalupe toca numa temática que já vinha se delineando anteriormente e que se tornará central no próximo livro de Angélica Freitas - Um útero é do tamanho de um punho (2012). Nos quadrinhos, os desdobramentos da narrativa vão paulatinamente investindo a heroína de poder. Na passada para o gênero lírico, a subjetividade se afasta para revelar os estereótipos que se acumulam ao longo dos séculos na construção do ser feminino.

Publicado em 2012, Um útero é do tamanho de um punho tem projeto temático bem definido: põe em xeque os estereótipos femininos criados por uma sociedade cis, hetero e patriarcal e dá voz ao empoderamento da mulher. O título do livro evidencia o caráter de luta e tomada de posicionamento da mulher em busca de seus direitos. Do mesmo modo que na sociedade patriarcal a mulher é vista metonimicamente pelo seu papel reprodutor, aquela que tem um útero para gerar e parir, no título inverte-se o sinal, e de símbolo de submissão o útero

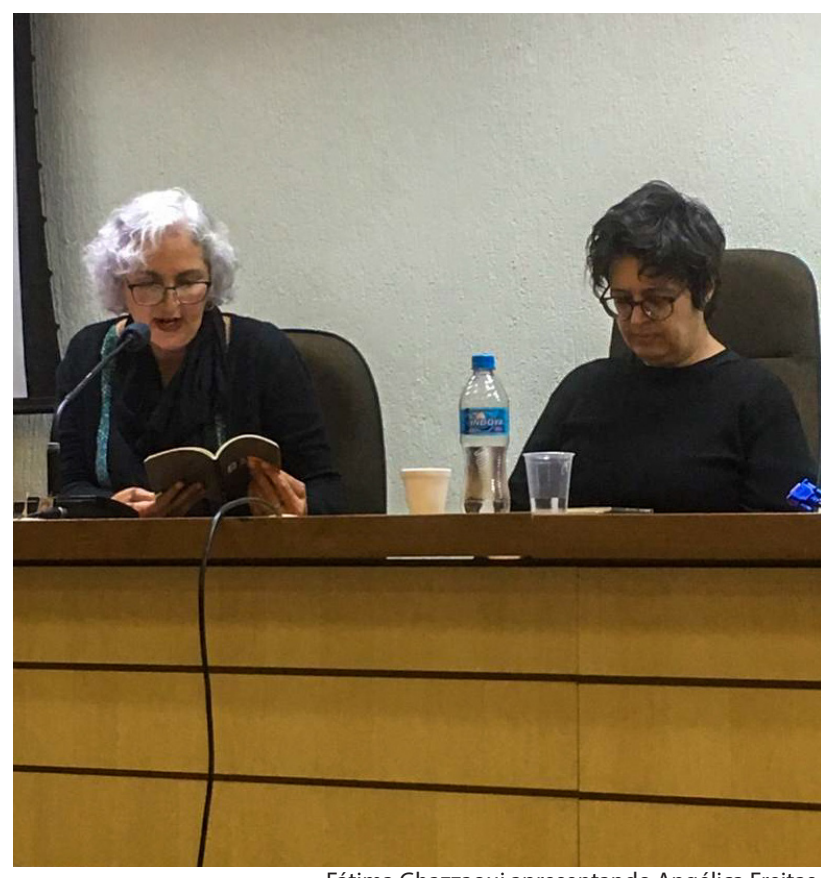

Fátima Ghazzaoui apresentando Angélica Freitas. Crédito da imagem: Beatriz Ramos Rodrigues 
passa a ser o instrumento de libertação e de luta. Cada parte do livro traz uma mulher construída socialmente como objeto que atende às expectativas dos outros. A mulher limpa, a mulher sedutora, a mulher de respeito, a mulher de posses, a mulher de vermelho, a mulher de regime, a mulher feia, a mulher de malandro... são figuras marcadas pela depreciação e redução a padrões estabelecidos. Na série intitulada "3 poemas com o auxílio do google", a pesquisa feita no site de busca permitiu enumerar os preconceitos que recaem sobre as mulheres e o quanto eles pesam na constituição subjetiva do feminino. Como fica evidente nos versos do poema "A mulher quer":

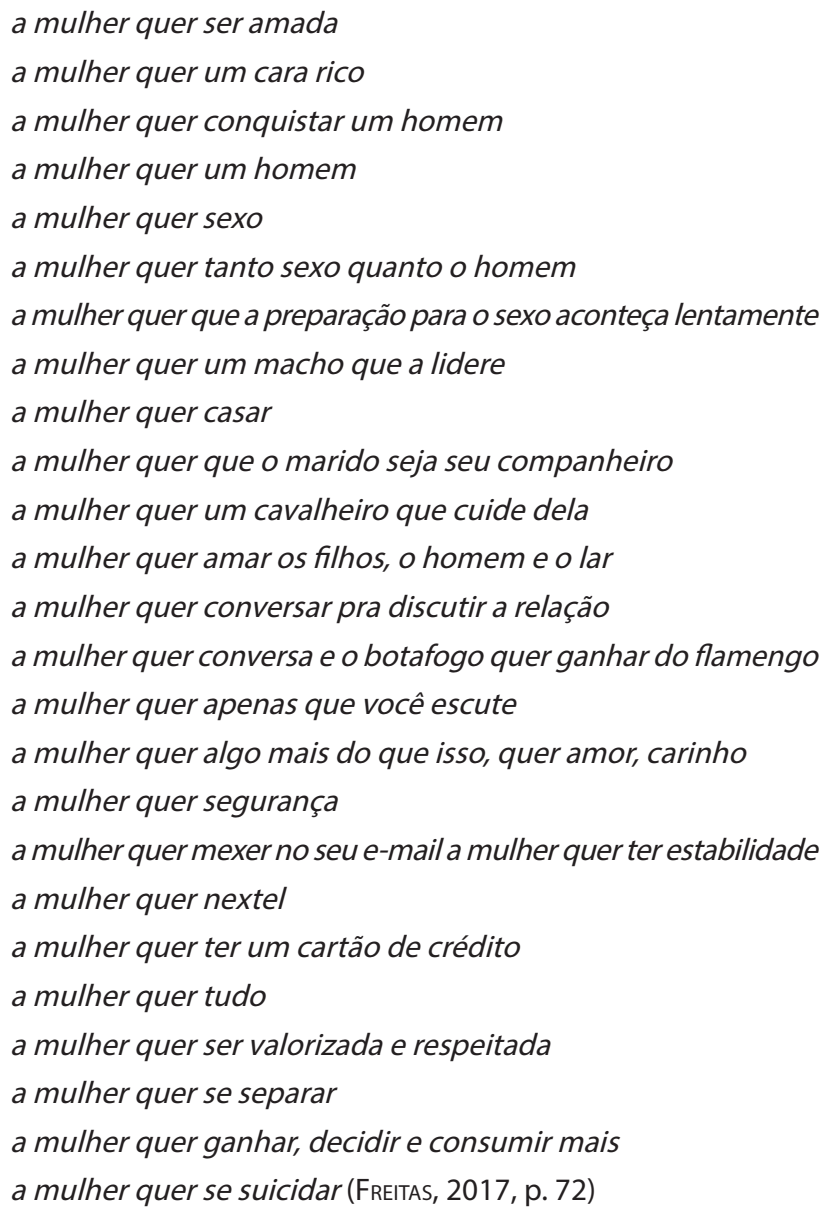





\section{REFERÊNCIAS BIBLIOGRÁFICAS}

AbDala Junior, Benjamin. Literatura, história e política. Literaturas de língua portuguesa do século XX. 3. ed. Cotia: Ateliê Editorial, 2017.

Bernardi, Odyr; Freitas, Angélica. Guadalupe. São Paulo: Companhia das Letras, 2012.

FreitAS, Angélica. Rilke Shake. São Paulo: Cosac Naify; Rio de Janeiro: 7Letras, 2007.

FreitAs, Angélica. Um útero é do tamanho de um punho. São Paulo: Companhia das Letras, 2017.

RILKE, Rainer Maria. Cartas a um jovem poeta. Trad. de Paulo Rónai e Cecília Meireles. 4. ed. São Paulo: Globo, 2013. 